\title{
Optimized loading test to evaluate responsiveness to tetrahydrobiopterin (BH4) in Brazilian patients with phenylalanine hydroxylase deficiency
}

\author{
Nalin, T ; Perry, I D ; Sitta, A ; Vargas, C R ; Saraiva-Pereira, M L ; Giugliani, R ; Blau, N ; Schwartz, \\ I V
}

\begin{abstract}
INTRODUCTION: Recent studies showed that phenylalanine (Phe) plasma concentrations may decrease in some patients with hyperphenylalaninemia (HPA) due to phenylalanine hydroxylase $(\mathrm{PAH})$ deficiency, after the administration of tetrahydrobiopterin $(\mathrm{BH}(4))$. OBJECTIVE: To determine responsiveness to a single dose of $\mathrm{BH}(4)$ administered according to an innovative protocol using a combined Phe and $\mathrm{BH}(4)$ loading test in Brazilian phenylketonuria (PKU) patients. METHODS: Patient age should be 4 years, and median Phe plasma concentration $600 \mathrm{~mol} / \mathrm{L}$ when following dietary restrictions. Participants received a simple Phe loading test using 100mg/kg L-Phe (Test 1) and a combined Phe+BH(4) loading test using $100 \mathrm{mg} / \mathrm{kg} \mathrm{L}-\mathrm{Phe}$ and $20 \mathrm{mg} / \mathrm{kg} / \mathrm{BH}(4)$ (Test 2). Blood samples were collected at baseline and 3, 11 and $27 \mathrm{~h}$ after Phe ingestion (T0, T1, T2 and T3). Responsiveness was defined as: criterion A: plasma Phe reduction of $30 \%$ at $\mathrm{T} 1$ and $\mathrm{T} 2$ for Tests 1 and 2; criterion B: plasma Phe reduction of $30 \%$ at T1 and T3 for Tests 1 and 2; and criterion C: at least 30\% difference of the areas under the Phe curve for Tests 1 and 2. RESULTS: Eighteen patients (median age 12 yrs; 8 classical PKU; 10 mild PKU) participated in the study. Six patients (2 classical PKU; 4 mild PKU) were classified as responsive according to at least one of the criteria. Responsiveness was concordant when criteria $\mathrm{A}+\mathrm{B}$ we compared with criterion $\mathrm{C}$ (kappa $=0.557 ; \mathrm{p}=0.017)$. Of the patients whose genotype was available $(\mathrm{n}=16)$, six had data about $\mathrm{BH}(4)$-responsiveness genotypes described in the literature, which were in agreement with our findings. CONCLUSION: The comparison of simple Phe loading and combined Phe $+\mathrm{BH}(4)$ loading seems to be an optimal method to evaluate responsiveness to $\mathrm{BH}(4)$ in patients with good metabolic control. Copyright (c) 2011 Elsevier Inc. All rights reserved.
\end{abstract}

DOI: https://doi.org/10.1016/j.ymgme.2011.09.019

Posted at the Zurich Open Repository and Archive, University of Zurich

ZORA URL: https://doi.org/10.5167/uzh-56815

Journal Article

Published Version

Originally published at:

Nalin, T; Perry, I D; Sitta, A; Vargas, C R; Saraiva-Pereira, M L; Giugliani, R; Blau, N; Schwartz, I V (2011). Optimized loading test to evaluate responsiveness to tetrahydrobiopterin (BH4) in Brazilian patients with phenylalanine hydroxylase deficiency. Molecular Genetics and Metabolism, 104(Suppl.):S80S85.

DOI: https://doi.org/10.1016/j.ymgme.2011.09.019 


\title{
Optimized loading test to evaluate responsiveness to tetrahydrobiopterin $\left(\mathrm{BH}_{4}\right)$ in Brazilian patients with phenylalanine hydroxylase deficiency
}

\author{
Tatiéle Nalin a , Ingrid Dalira Schweigert Perry b , Angela Sitta c, Carmen Regla Vargas c,d,e, \\ Maria Luiza Saraiva-Pereira d,f , Roberto Giugliani a,d,g,h, \\ Nenad Blau ${ }^{\mathrm{i}, \mathrm{j}}$, Ida Vanessa Doederlein Schwartz ${ }^{\mathrm{a}, \mathrm{d}, \mathrm{g}, *}$ \\ ${ }^{a}$ Post-Graduation Program in Medicine: Medical Sciences, Universidade Federal do Rio Grande do Sul, Porto Alegre, Brazil \\ ${ }^{\mathrm{b}}$ Department of Internal Medicine, Universidade Federal do Rio Grande do Sul. Food and Nutrition Research Center of Hospital de Clínicas de Porto Alegre, Porto Alegre, Brazil \\ c Post-Graduation Program in Biochemistry, Universidade Federal do Rio Grande do Sul, Porto Alegre, Brazil \\ d Medical Genetics Service, Hospital de Clínicas de Porto Alegre, Porto Alegre, Brazil \\ e School of Pharmacy, Universidade Federal do Rio Grande do Sul, Porto Alegre, Brazil \\ ${ }^{\mathrm{f}}$ Department of Biochemistry, Universidade Federal do Rio Grande do Sul, Porto Alegre, Brazil \\ ${ }^{g}$ Department of Genetics, Universidade Federal do Rio Grande do Sul, Porto Alegre, Brazil \\ h INAGEMP - Instituto Nacional de Genética Médica Populacional, Porto Alegre, Brazil \\ ${ }^{i}$ Division of Clinical Chemistry, University Children's Hospital, Zürich, Switzerland \\ j Zürich Center for Integrative Human Physiology (ZIHP), Zürich, Switzerland
}

\section{A R T I C L E I N F O}

\section{Article history}

Received 27 July 2011

Received in revised form 13 September 2011

Accepted 13 September 2011

Available online 20 September 2011

\section{Keywords:}

Inborn errors of metabolism

Hyperphenylalaninemia

Phenylketonuria

Phenylalanine

Tetrahydrobiopterin

\begin{abstract}
A B S T R A C T
Introduction: Recent studies showed that phenylalanine (Phe) plasma concentrations may decrease in some patients with hyperphenylalaninemia ( $\mathrm{HPA}$ ) due to phenylalanine hydroxylase (PAH) deficiency, after the administration of tetrahydrobiopterin $\left(\mathrm{BH}_{4}\right)$.

Objective: To determine responsiveness to a single dose of $\mathrm{BH}_{4}$ administered according to an innovative protocol using a combined Phe and $\mathrm{BH}_{4}$ loading test in Brazilian phenylketonuria (PKU) patients.

Methods: Patient age should be $\geq 4$ years, and median Phe plasma concentration $\leq 600 \mu \mathrm{mol} / \mathrm{L}$ when following dietary restrictions. Participants received a simple Phe loading test using $100 \mathrm{mg} / \mathrm{kg} \mathrm{L}$-Phe (Test 1 ) and a combined Phe $+\mathrm{BH}_{4}$ loading test using $100 \mathrm{mg} / \mathrm{kg}$ L-Phe and $20 \mathrm{mg} / \mathrm{kg} / \mathrm{BH}_{4}$ (Test 2). Blood samples were collected at baseline and 3,11 and $27 \mathrm{~h}$ after Phe ingestion (T0, T1, T2 and T3). Responsiveness was defined as: criterion A: plasma Phe reduction of $\geq 30 \%$ at T1 and T2 for Tests 1 and 2 ; criterion B: plasma Phe reduction of $\geq 30 \%$ at $\mathrm{T} 1$ and $\mathrm{T} 3$ for Tests 1 and 2; and criterion C: at least 30\% difference of the areas under the Phe curve for Tests 1 and 2.

Results: Eighteen patients (median age 12 yrs; 8 classical PKU; 10 mild PKU) participated in the study. Six patients ( 2 classical PKU; 4 mild PKU) were classified as responsive according to at least one of the criteria. Responsiveness was concordant when criteria $A+B$ we compared with criterion $C$ (kappa $=0.557 ; p=0.017$ ). Of the patients whose genotype was available $(n=16)$, six had data about $\mathrm{BH}_{4}$-responsiveness genotypes described in the literature, which were in agreement with our findings.

Conclusion: The comparison of simple Phe loading and combined Phe $+\mathrm{BH}_{4}$ loading seems to be an optimal method to evaluate responsiveness to $\mathrm{BH}_{4}$ in patients with good metabolic control.
\end{abstract}

(c) 2011 Elsevier Inc. All rights reserved.

\section{Introduction}

Phenylketonuria (PKU) or hyperphenylalaninemia due to phenylalanine hydroxylase (PAH) deficiency is an inborn error of amino acid metabolism characterized by the persistent increase of phenylalanine (Phe) plasma concentration. PAH converts Phe into tyrosine (Tyr), in the presence of its cofactor tetrahydrobiopterin $\left(\mathrm{BH}_{4}\right)$ [1].

\footnotetext{
* Corresponding author at: Serviço de Genética Médica, Hospital de Clínicas de Porto Alegre, Rua Ramiro Barcelos 2350, 90035-903 Porto Alegre, RS, Brazil.

E-mail address: ischwartz@hcpa.ufrgs.br (I.V.D. Schwartz).
}

The standard PKU treatment is based on a Phe-restricted diet and ingestion of a Phe-free amino acid-rich metabolic formula that supplies the daily protein requirements of a patient $[1,2]$. Because of the toxic effects of high Phe levels, this condition, if left untreated, may lead to neurological impairment, mental retardation and behavioral disorders $[3,4]$.

The necessary dietary restriction and the associated difficulty to adhere to the treatment [4-6], have motivated the search for new PKU management strategies [7]. Since the publication of the study by Kure et al. [8], who described the first case of patients with PKU whose Phe levels decreased after $\mathrm{BH}_{4}$ administration, several studies 
have been conducted to confirm the efficacy and safety of this medication, which has already been approved by the FDA and the EMEA. Patients are usually evaluated to check their responsiveness and, in case results suggest that they are responsive, that is, that Phe levels will decrease after $\mathrm{BH}_{4}$ administration, $\mathrm{BH}_{4}$ supplementation is initiated. Studies, however, have used different protocols to evaluate responsiveness: $\mathrm{BH}_{4}$ doses are different and may range from 10 to $20 \mathrm{mg} / \mathrm{kg} /$ day in a single dose or distributed along the day; test evaluation times range from some hours to weeks or even months; the cut-off point of Phe variation defined to determine responsiveness also varies, and the criterion most frequently adopted is a decrease of $30 \%$ in Phe levels $24 \mathrm{~h}$ after $\mathrm{BH}_{4}$ administration. In addition, different diets are used during tests: normal diets, Phe-restricted diet, or even a Phe-loading diet using, for example, powder milk or L-Phe [7,9-22].

This study describes responsiveness to a single dose of $\mathrm{BH}_{4}$ in a sample of Brazilian patients with PKU and good metabolic control. For that purpose, an innovative protocol with a single Phe plus a combined Phe and $\mathrm{BH}_{4}$ loading tests was used.

\section{Material and methods}

This study included patients with PKU seen in the Outpatient Metabolic Disorder Treatment Clinic of the Medical Genetics Service of Hospital de Clínicas de Porto Alegre (ATDM-SGM/HCPA), Porto Alegre, Brazil. At the time this study was conducted, 68 patients with different phenotypes were followed up in the ATDM-SGM/HCPA and 64 of them underwent dietary treatment.

This study was approved by the Ethics in Research Committee of $\mathrm{HCPA}$, and all patients or their guardians signed a written informed consent term.

\subsection{Patients}

Patients included in the study should be aged $\geq 4$ years and should be under dietary treatment; median Phe plasma levels should be $\leq 600 \mu \mathrm{mol} / \mathrm{L}$ in the 12 months before the start of the study. The Phe cut-off point adopted ensured that patients with the mild form of the disease, good metabolic control, or both were also included in the test. A previous trial conducted by our study team [23] adopted a different protocol and different inclusion criteria to evaluate responsiveness to $\mathrm{BH}_{4}$, and most patients had the classical form of the disease and inadequate metabolic control, as their Phe plasma levels had to be $\geq 360 \mu \mathrm{mol} / \mathrm{L}$ in all measurements during the previous 12 months.

Exclusion criteria were: pregnancy, clinical signs suggestive of liver disease; use of levodopa; allergy to any component of $\mathrm{BH}_{4}$; median Phe level $>600 \mu \mathrm{mol} / \mathrm{L}$ in the measurements made in the 12 months before inclusion in the study; irregular follow-up in the ATDM-SGM/ HCPA in the same 12 months; and probable non-compliance with study procedures according to evaluations made by the authors.

PKU types were defined according to Nalin et al. [6], and the patients were classified as having classical PKU or mild PKU.

\subsection{Single Phe and combined Phe $+\mathrm{BH}_{4}$ loading tests}

The patients were asked to come to two visits in HCPA and to stay under evaluation for $27 \mathrm{~h}$ each time; the two visits were made at a one-week interval.

\subsubsection{Simple Phe loading (Test 1)}

In the first week, after overnight fasting, blood was collected to measure Phe and Tyr plasma concentrations (T0). After that, patients ingested $100 \mathrm{mg} / \mathrm{kg}$ of L-Phe and resumed their usual diet (Pherestricted diet and supplementation with Phe-free metabolic formula). Blood for Phe and Tyr was then collected at 3 (T1), 11 (T2) and $27 \mathrm{~h}$ (T3) after Phe loading.

\subsubsection{Combined Phe and $\mathrm{BH}_{4}$ loading (Test 2)}

In the second week, evaluation was conducted using the protocol described by Blau et al. [24], with a modification, as Phe and Tyr levels were not analyzed $7 \mathrm{~h}$ after Phe loading. The initial phases of Test 2 (collection at T0, Phe loading, food ingestion, and blood collection at T1) were similar to those described for Test 1 . In addition, immediately after collection at T1 bloods sample, a single dose of $20 \mathrm{mg} / \mathrm{kg}$ $\mathrm{BH}_{4}$ (sapropterin dihydrochloride, KUVAN®, Merck Serono) was administered orally and samples were collected at $8 \mathrm{~h}$ (T2) and $24 \mathrm{~h}$ (T3) after $\mathrm{BH}_{4}$ ingestion. Time points T0 and T1 of Tests 1 and 2 were, therefore, equivalent to each other, whereas T2 and T3 were differed in that $\mathrm{BH}_{4}$ administration was included in Test 2.

L-Phe and $\mathrm{BH}_{4}$ were dissolved in orange juice before administration. Patients were told to fast for at least $1 \mathrm{~h}$ before all blood collections.

Phe and Tyr plasma concentrations were measured using tandem mass spectrometry (MS/MS) in the Laboratory of Inborn Errors of Metabolism of SGM/HCPA, as described by Rashed et al. [25]. All measurements were made in duplicate, and the mean of the two measurements was calculated. In Test 2 samples, the levels of $\mathrm{BH}_{4}$ (total biopterins) were also measured, according to the method of Opladen et al. [26].

\subsection{Responsiveness to $\mathrm{BH}_{4}$}

Patients were defined as responsive to $\mathrm{BH}_{4}$ if they met at least one of the criteria listed below:

Criterion A: this criterion used Phe values at T1 [3 h after Phe loading in Tests 1 (1T1) and 2 (2T1)] and at T2 [11 h after Phe loading in Tests 1 (1T2) and 2 (2T2) and $8 \mathrm{~h}$ after $\mathrm{BH}_{4}$ administration in Test $2]$. The following equation was used for calculations: [((2T2$2 \mathrm{~T} 1) / 2 \mathrm{~T} 1) \times 100]-[((1 \mathrm{~T} 2-1 \mathrm{~T} 1) / 1 \mathrm{~T} 1) \times 100]$.

Individuals were responsive if the values found corresponded to a reduction of $\geq 30 \%$ in Phe levels in Test 2 .

Criterion B: this criterion used Phe values at T1 and T3 [27 h after Phe loading in Tests 1 (1T3) and 2 (2T3) and $24 \mathrm{~h}$ after $\mathrm{BH}_{4}$ administration in Test 2]. The following equation was used for calcu-

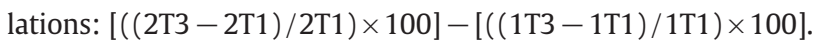
Individuals were responsive if the values found corresponded to a reduction of $\geq 30 \%$ in Phe levels in Test 2 .

Criterion C: this criterion used the percentage difference of the value found for the area under the Phe curve in Tests 1 (AUC1) and 2 (AUC2). The following equation was used for calculations: [( AUC2 - AUC1)/AUC1 $) \times 100]$. Individuals were responsive if the difference was $\geq 30 \%$, as long as the Test 1 area was greater than the Test 2 area.

To compare the classification of responsiveness, four additional criteria were used, as described below:

Criterion D: only the Phe values at T1 and T2 of Test 2 were used. The following equation was used for calculations: [((2T2-2T1)/2T1) $\times$ $100]$. Individuals were responsive if the values found corresponded to a reduction of $\geq 30 \%$ in Phe levels in time point 2 .

Criterion E: only the Phe values at T1 and 3 of Test 2 were used. The following equation was used for calculations: [((2T3-2T1)/2T1) $\times$ $100]$. Individuals were responsive if the values found corresponded to a reduction of $\geq 30 \%$ in Phe levels in time point 3 .

Criterion F: this criterion was used by the authors in a previous study [23] to evaluate the responsiveness of 5 patients also included in this study, and was defined as a reduction of $\geq 30 \%$ in Phe levels $8 \mathrm{~h}$ after simple $\mathrm{BH}_{4}$ loading (singledose of $\mathrm{BH}_{4}$ at $20 \mathrm{mg} / \mathrm{kg}$, without a concomitant load of Phe or L-Phe). 
Criterion G: this criterion was used by the authors in a previous study [23] to evaluate the responsiveness of 5 patients also included in this study, and was defined as a reduction of $\geq 30 \%$ in Phe levels $24 \mathrm{~h}$ after simple $\mathrm{BH}_{4}$ loading.

\subsection{Dietary intake of Phe}

Phe intake was evaluated using food recalls on the day before and on the first day of Tests 1 and 2, which totaled, therefore, two recalls for each Test. Dietary Phe intake was calculated using the nutritionsupport software NutriBase (NB7), Clinical Edition. All patients received instructions to keep the same dietary Phe prescription that they followed before the beginning of the study.

\subsection{Genotype}

Genotypes of patients 1 to 17 (Table 1 ) were established previously and retrieved from their medical charts. Patient 18 was the only patient who had not been genotyped at the time of the study.

\subsection{Statistical analysis}

The Statistical Package for Social Sciences 18.0 (SPSS ${ }^{\circledR}$ Inc., Chicago, IL) was used for statistical analysis. Data were described using absolute and relative frequencies. The Stata program was used to calculate the area under the Phe curve. Continuous variables were expressed as mean \pm standard deviation or median and interquartile range. The Shapiro-Wilk test was used to analyze variable distribution.

The Student $t$ test was used to compare Phe intake between the different food recalls, the area under the Phe curve, and the difference in Phe levels between the collection time points for responsive patients versus non-responsive patients. Phe plasma concentrations and Phe:Tyr ratios were analyzed using Generalized Estimating Equations and Bonferroni correction. The comparison between $\mathrm{BH}_{4}$ responsiveness criteria was made using kappa statistics.

The level of significance was set at $5 \%$.

\section{Results}

Eighteen patients ( 11 girls and 7 boys) from 16 nonrelated families were included in the study. Parental consanguinity was found in $1 / 16$ (6.25\%) family. Median patient age was 12 (interquartile range: 10 16.5 ) years; minimum age was 6 , and maximum, 31 years.

Mean Phe levels in Tests 1 and 2 at T0 were $255 \pm 138$ and $333 \pm$ $173 \mu \mathrm{mol} / \mathrm{L}(\mathrm{n}=18 ; \mathrm{p}=0.342)$, and at $\mathrm{T} 1,730 \pm 221$ and $790 \pm 310$ $(\mathrm{n}=18 ; \mathrm{p}=1.0)$. In both Tests 1 and 2 there were significant increases in Phe levels between T0 and T1 $(\mathrm{p}<0.01)$. There were no statistically significant differences in Phe:Tyr ratios when the same time points were compared between Tests 1 and 2 .

$\mathrm{BH}_{4}$ plasma levels in Test 2 increased after L-Phe administration (T1) and $\mathrm{BH}_{4}$ loading (T2) (data not reported).

\subsection{Response to $\mathrm{BH}_{4}$}

Six patients (33.3\%) were responsive, four according to criterion A, three according to criterion $\mathrm{B}$, and four according to criterion $\mathrm{C}$ (Table 2). The comparison of BH4-responsiveness according to criterion used is shown in Table 3. In the calculation of the Kappa Index, the data reported by Giugliani et al. [23] were not included because of the small sample size (5/18 patients included in this study). Kappa was 0.557 when criteria A + B were compared with criterion $C(p=0.017)$. For the other criteria, Kappa values indicated a weak agreement.

For responsive patients, mean Phe level variations between time points T1 and T2 and between time points T1 and T3 were different only in Test $2(\mathrm{p}=0.002$ and 0.011 , respectively), that difference was not found for non-responsive patients (Table 2). The analysis of area under the curve (AUC) revealed a statistically significant difference between Tests 1 and 2 mean values for responsive patients $(p<0.01)$, but not for non-responsive patients $(p=0.242)$ (Table 2).

Fig. 1 shows the Phe plasma concentration values found in this study according to collection time point in Tests 1 and 2 for a $\mathrm{BH}_{4}{ }^{-}$ responsive patient (Fig. 1A) and a non-responsive patient (Fig. 1B).

Table 1

Genotype, PKU phenotype for each patient and comparison of responsiveness in this study with findings in the literature.

\begin{tabular}{|c|c|c|c|c|c|c|}
\hline \multirow[t]{2}{*}{ Patient } & \multirow{2}{*}{$\begin{array}{l}\text { Type of } \\
\text { PKU }\end{array}$} & \multicolumn{2}{|l|}{ Genotype } & \multirow{2}{*}{$\begin{array}{l}\text { Responsiveness to } \mathrm{BH}_{4}^{\mathrm{a}} \\
\text { (our study) }\end{array}$} & \multirow{2}{*}{$\begin{array}{l}\text { Responsiveness to } \mathrm{BH}_{4} \\
\text { (number of patients included) }\end{array}$} & \multirow[t]{2}{*}{ Protocol used in the literature ${ }^{c}$} \\
\hline & & Allele 1 & Allele 2 & & & \\
\hline 1 & Classical & p.I65T & p.R408W & $\mathrm{R}$ & $\mathrm{R}(2)$ & $\mathrm{BH}_{4}(10 \mathrm{mg})-24 \mathrm{~h}$ \\
\hline 2 & Classical & p.V388M & p.V388M & $\mathrm{R}$ & $R(1)-$ Slow $R(1)^{d}$ & $\mathrm{BH}_{4}(20 \mathrm{mg})-24 \mathrm{~h}$ \\
\hline 3 & Classical & p.I65T & p.R176X & NR & $\mathrm{Nd}$ & Nd \\
\hline 4 & Classical & p.R252W & p.R261Q & NR & $\mathrm{Nd}$ & $\mathrm{Nd}$ \\
\hline 5 & Classical & p.165T & p.I65T & NR & NR (1) & Phe $(100 \mathrm{mg}) / \mathrm{BH}_{4}(20 \mathrm{mg})-8 \mathrm{~h}$ \\
\hline 6 & Mild & p.E390G & p.R408Q & $\mathrm{R}$ & $\mathrm{Nd}$ & $\mathrm{Nd}$ \\
\hline 7 & Classical & p.R261X & p.R176X & NR & $\mathrm{Nd}$ & $\mathrm{Nd}$ \\
\hline 8 & Mild & p.R408W & c.165delT & NR & $\mathrm{Nd}$ & $\mathrm{Nd}$ \\
\hline 9 & Mild & p.R408W & c.165delT & NR & $\mathrm{Nd}$ & $\mathrm{Nd}$ \\
\hline 10 & Mild & p.E390G & p.A104D & $\mathrm{R}$ & $\mathrm{Nd}$ & $\mathrm{Nd}$ \\
\hline 11 & Mild & p.R408W & p.L348V & NR & $\mathrm{Nd}$ & $\mathrm{Nd}$ \\
\hline 12 & Mild & p.R408W & p.L348V & NR & $\mathrm{Nd}$ & $\mathrm{Nd}$ \\
\hline 13 & Mild & p.A300S & p.L311P & $\mathrm{R}$ & $\mathrm{Nd}$ & $\mathrm{Nd}$ \\
\hline 14 & Classical & p.R408W & p.R408W & NR & NR(13) Slow R (1) ${ }^{d}$ & $\mathrm{BH}_{4}(20 \mathrm{mg})-24 \mathrm{~h}(13) /$ Other (1) \\
\hline 15 & Mild & p.R261Q & p.V388M & $\mathrm{R}$ & $\mathrm{R}(1)$ & $\mathrm{BH}_{4}(10 \mathrm{mg})-8 \mathrm{~h}$ \\
\hline 16 & Mild & p.L249F & p.V388M & NR & NR (1) & $\mathrm{BH}_{4}(20 \mathrm{mg})-24 \mathrm{~h}$ \\
\hline 17 & Classical & c.165delT & $?$ & NR & - & - \\
\hline 18 & Mild & $?$ & $?$ & NR & - & - \\
\hline
\end{tabular}

PKU: phenylketonuria; Nd: not described; R: Responsive; NR: non-responsive; Siblings: 8 and 9; 11 and 12.

a To be classified as responsive, patient had to obtain a positive result according to at least one of the criteria used (criteria A, B and C).

b Data retrieved from BIOPKUdb http://www.bh4.org/BH4DatabasesBioHPA-PAH.asp.

c Loading protocol used in other PKU patients with the same genotype (amount of $\mathrm{BH}_{4}$ per kg of current weight; time used for responsiveness criterion).

d Patients with a Phe reduction of 20 to $30 \%$ after $\mathrm{BH}_{4}$ loading. 
Table 2

$\mathrm{BH}_{4}$ responsiveness: Phe values and corresponding areas under the curve ( $\mathrm{n}=18$ patients).

\begin{tabular}{|c|c|c|c|c|c|c|c|c|c|c|c|}
\hline \multirow[t]{3}{*}{ Patients } & \multicolumn{3}{|l|}{ Test 1} & \multicolumn{3}{|l|}{ Test 2} & \multicolumn{2}{|c|}{ Area under Phe curve } & \multirow{3}{*}{$\begin{array}{l}\text { Criterion A } \\
(\%)\end{array}$} & \multirow{3}{*}{$\begin{array}{l}\text { Criterion B } \\
(\%)\end{array}$} & \multirow{3}{*}{$\begin{array}{l}\text { Critérion C } \\
(\%)\end{array}$} \\
\hline & \multicolumn{3}{|c|}{ Phe $(\mu \mathrm{mol} / \mathrm{L})$} & \multicolumn{3}{|c|}{ Phe $(\mu \mathrm{mol} / \mathrm{L})$} & \multirow[t]{2}{*}{ AUC1 } & \multirow[t]{2}{*}{ AUC2 } & & & \\
\hline & $\mathrm{T} 1$ & $\mathrm{~T} 2$ & T3 & $\mathrm{T} 1$ & $\mathrm{~T} 2$ & T3 & & & & & \\
\hline \multicolumn{12}{|c|}{ Responsive } \\
\hline 1 & 852 & 1032 & 949 & 1010 & 823 & 816 & 373.1 & 289.8 & -39.6 & -30.6 & -22.3 \\
\hline 2 & 1193 & 1314 & 849 & 939 & 895 & 639 & 435.2 & 297.2 & -14.8 & -3.1 & -31.7 \\
\hline 6 & 588 & 474 & 136 & 570 & 144 & 74,8 & 133.8 & 27.9 & -55.3 & -10 & -79.1 \\
\hline 10 & 522 & 372 & 113 & 612 & 127 & 58,4 & 103.1 & 19.3 & -50.5 & -12.1 & -81.3 \\
\hline 13 & 744 & 602 & 550 & 748 & 516 & 189 & 207.1 & 145.2 & -11.9 & -48.6 & -29.9 \\
\hline 15 & 657 & 822 & 589 & 819 & 498 & 355 & 281.6 & 153.1 & -64.3 & -46.3 & -45.6 \\
\hline$\mu \pm s d$ & $759 \pm 242$ & $769 \pm 358$ & $531 \pm 349$ & $783 \pm 175^{*}$ & $500 \pm 324^{*}$ & $355 \pm 312^{*}$ & $255.6 \pm 132.0^{* *}$ & $155.4 \pm 120.9^{* *}$ & $-39.4 \pm 21.7$ & $-25.1 \pm 19.5$ & $-48.3 \pm 25.8$ \\
\hline \multicolumn{12}{|c|}{ Non-responsive } \\
\hline 3 & 1095 & 750 & 706 & 991 & 946 & 808 & 253.2 & 327.3 & 27 & 17 & 29.3 \\
\hline 4 & 702 & 555 & 462 & 496 & 553 & 390 & 185.9 & 186.6 & 32.4 & 12.8 & 0.4 \\
\hline 5 & 517 & 427 & 530 & 652 & 661 & 494 & 161.1 & 223.4 & 18.7 & -26.7 & 38.6 \\
\hline 7 & 816 & 775 & 617 & 634 & 696 & 542 & 263.5 & 239.5 & 14.8 & 9.9 & -9.1 \\
\hline 8 & 367 & 425 & 390 & 699 & 726 & 715 & 152.9 & 263.0 & -11.9 & -3.9 & 72.0 \\
\hline 9 & 544 & 626 & 486 & 742 & 736 & 730 & 216.4 & 265.8 & -15.8 & 9 & 22.8 \\
\hline 11 & 836 & 655 & 613 & 608 & 513 & 418 & 225.7 & 172.6 & 6 & -4.5 & -23.5 \\
\hline 12 & 991 & 925 & 717 & 1095 & 855 & 660 & 311.9 & 280.7 & -15.2 & -12 & -10.0 \\
\hline 14 & 711 & 562 & 296 & 587 & 421 & 197 & 171.3 & 123.6 & -7.3 & -8 & -27.8 \\
\hline 16 & 789 & 640 & 446 & 714 & 637 & 422 & 206.6 & 206.4 & 8.1 & 2.5 & -0.1 \\
\hline 17 & 790 & 810 & 799 & 1810 & 1787 & 1398 & 293.2 & 608.1 & -3.8 & -23.9 & 107.4 \\
\hline 18 & 422 & 350 & 227 & 489 & 304 & 208 & 111.7 & 93.1 & -20.8 & -11.2 & -16.7 \\
\hline$\mu \pm s d$ & $715 \pm 220$ & $625 \pm 172$ & $524 \pm 174$ & $793 \pm 367$ & $736 \pm 375$ & $582 \pm 323$ & $212.8 \pm 60.0$ & $249.2 \pm 131.0$ & $2.6 \pm 17.8$ & $-3.2 \pm 14$ & $15.3 \pm 41.1$ \\
\hline
\end{tabular}

Phe: phenylalanine; Test 1: simple Phe loading; Test 2: combined Phe $+\mathrm{BH}_{4}$ loading; Siblings: 8 and $9 ; 11$ and 12.

Criterion A: $[((2 \mathrm{~T} 2-2 \mathrm{~T} 1) / 2 \mathrm{~T} 1) \times 100]-[((1 \mathrm{~T} 2-1 \mathrm{~T} 1) / 1 \mathrm{~T} 1) \times 100]$

Criterion B: $[((2 \mathrm{~T} 3-2 \mathrm{~T} 1) / 2 \mathrm{~T} 1) \times 100]-[((1 \mathrm{~T} 3-1 \mathrm{~T} 1) / 1 \mathrm{~T} 1) \times 100]$.

Criterion C: [((AAC2 - AAC1)/AAC1) × 100].

To be classified as responsive, patient had to obtain a positive result according to at least one of the criteria used (criteria $\mathrm{A}, \mathrm{B}$ and $\mathrm{C}$ ).

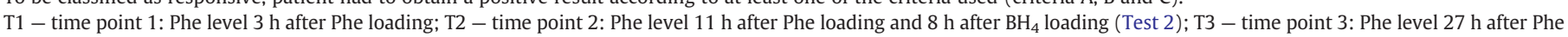
loading and $24 \mathrm{~h}$ after $\mathrm{BH}_{4}$ loading (Test 2); AUC1: Area under the curve in Test 1; AUC2: Area under the curve in Test 2.

* Phe variation between T2 and T1 and between T3 and T1 was statistically significant $(\mathrm{p}=0.002$ and 0.011$)$.

** Statistically significant difference $(\mathrm{p}<0.01)$.

\subsection{Association between genotype and responsiveness to $\mathrm{BH}_{4}$ (Table 1)}

Data about the genotype, severity of PKU and BH4-responsiveness are shown in Table 1.

\subsection{Dietary intake}

The patients ingested in average $705.56 \pm 356.77$ and $608.89 \pm$ $405.51 \mathrm{mg}$ (mean \pm SD) of Phe per day, according to dietary recalls 1 and 2 of Test $1(p=0.446)$, and $672.78 \pm 406.17$ and $572.78 \pm$ $329.47 \mathrm{mg}$ (mean $\pm \mathrm{SD}$ ) of Phe per day according to dietary recalls 1 and 2 of Test $2(p=0.281)$. There were no statistically significant differences in Phe intake between Tests 1 (657.2 $\pm 379.6 \mathrm{mg}$ Phe/day) and $2(622.7 \pm 368 \mathrm{mg}$ Phe/day $)(\mathrm{p}=0.564)$.

\section{Discussion}

In this study, patients with PKU that might potentially benefit from the use of $\mathrm{BH}_{4}$ were identified by comparing their Phe levels after a simple Phe loading test and after a combined $\mathrm{Phe}+\mathrm{BH}_{4}$ loading test. Although no consensus has been reached in the literature about the most adequate method to identify these individuals, Phe plasma levels should be elevated at the time of $\mathrm{BH}_{4}$ administration to induce an increase in $\mathrm{PAH}$ activity and, consequently, to potentiate the effect of $\mathrm{BH}_{4}$ [27]. This recommendation adds complexity to the investigation of $\mathrm{BH}_{4}$ responsiveness in patients with good adherence to dietary treatment. The increase of Phe levels is often achieved by increasing the ingestion of dietary Phe $[8,9,20,22,28-30]$, which may raise ethical and psychological issues. A single Phe dose using L-Phe may also be administered, with the advantage that the patient's diet does not have to be changed [19,31-33]; however, Phe levels after this type of loading tend to spontaneously decrease in $24 \mathrm{~h}$ even when $\mathrm{BH}_{4}$ is not been administered [20,32]. Therefore, $\mathrm{BH}_{4}$ responsiveness would have to be confirmed by comparing Phe plasma levels after the Phe $+\mathrm{BH}_{4}$ loading test and after the simple Phe loading test. We have found in the literature only two studies performing the simple Phe loading test and the combined Phe $+\mathrm{BH}_{4}$ loading test in the

Table 3

$\mathrm{BH}_{4}$ responsiveness according to criteria used for classification in this study.

\begin{tabular}{lccccccc}
\hline Patients & $\begin{array}{c}\text { Criterion } \\
\text { A Criterion }\end{array}$ & Criterion & $\begin{array}{c}\text { Criterion } \\
\mathrm{B}\end{array}$ & $\mathrm{C}$ & $\mathrm{D}$ & $\begin{array}{c}\text { Criterion } \\
\text { Criterion }\end{array}$ & $\begin{array}{c}\text { Criterion } \\
\mathrm{F}^{\mathrm{a}}\end{array}$ \\
\hline 1 & $\mathrm{R}$ & $\mathrm{R}$ & $\mathrm{NR}$ & $\mathrm{NR}$ & $\mathrm{NR}$ & $\mathrm{NR}$ & $\mathrm{R}$ \\
2 & $\mathrm{NR}$ & $\mathrm{NR}$ & $\mathrm{R}$ & $\mathrm{NR}$ & $\mathrm{R}$ & - & - \\
3 & $\mathrm{NR}$ & $\mathrm{NR}$ & $\mathrm{NR}$ & $\mathrm{NR}$ & $\mathrm{NR}$ & $\mathrm{R}$ & $\mathrm{R}$ \\
4 & $\mathrm{NR}$ & $\mathrm{NR}$ & $\mathrm{NR}$ & $\mathrm{NR}$ & $\mathrm{NR}$ & - & - \\
5 & $\mathrm{NR}$ & $\mathrm{NR}$ & $\mathrm{NR}$ & $\mathrm{NR}$ & $\mathrm{NR}$ & - & - \\
6 & $\mathrm{R}$ & $\mathrm{NR}$ & $\mathrm{R}$ & $\mathrm{R}$ & $\mathrm{R}$ & - & - \\
7 & $\mathrm{NR}$ & $\mathrm{NR}$ & $\mathrm{NR}$ & $\mathrm{NR}$ & $\mathrm{NR}$ & - & - \\
8 & $\mathrm{NR}$ & $\mathrm{NR}$ & $\mathrm{NR}$ & $\mathrm{NR}$ & $\mathrm{NR}$ & - & - \\
9 & $\mathrm{NR}$ & $\mathrm{NR}$ & $\mathrm{NR}$ & $\mathrm{NR}$ & $\mathrm{NR}$ & - & - \\
10 & $\mathrm{R}$ & $\mathrm{NR}$ & $\mathrm{R}$ & $\mathrm{R}$ & $\mathrm{R}$ & - & - \\
11 & $\mathrm{NR}$ & $\mathrm{NR}$ & $\mathrm{NR}$ & $\mathrm{NR}$ & $\mathrm{R}$ & $\mathrm{R}$ & $\mathrm{R}$ \\
12 & $\mathrm{NR}$ & $\mathrm{NR}$ & $\mathrm{NR}$ & $\mathrm{NR}$ & $\mathrm{R}$ & $\mathrm{NR}$ & $\mathrm{NR}$ \\
13 & $\mathrm{NR}$ & $\mathrm{R}$ & $\mathrm{NR}$ & $\mathrm{R}$ & $\mathrm{R}$ & - & - \\
14 & $\mathrm{NR}$ & $\mathrm{NR}$ & $\mathrm{NR}$ & $\mathrm{NR}$ & $\mathrm{R}$ & - & - \\
15 & $\mathrm{R}$ & $\mathrm{R}$ & $\mathrm{R}$ & $\mathrm{R}$ & $\mathrm{R}$ & - & - \\
16 & $\mathrm{NR}$ & $\mathrm{NR}$ & $\mathrm{NR}$ & $\mathrm{NR}$ & $\mathrm{R}$ & $\mathrm{NR}$ & $\mathrm{NR}$ \\
17 & $\mathrm{NR}$ & $\mathrm{NR}$ & $\mathrm{NR}$ & $\mathrm{NR}$ & $\mathrm{NR}$ & - & - \\
18 & $\mathrm{NR}$ & $\mathrm{NR}$ & $\mathrm{NR}$ & $\mathrm{R}$ & $\mathrm{R}$ & - & - \\
\hline
\end{tabular}

$\mathrm{R}=$ responsive; $\mathrm{NR}=$ non-responsive

The criteria are defined in the Material and methods section of this study. Siblings: 8 and 9; 11 and 12 .

a Data reported by Giugliani et al. [23]. 
A Patient 6 - Mild PKU (p.E390G/p.R408Q)

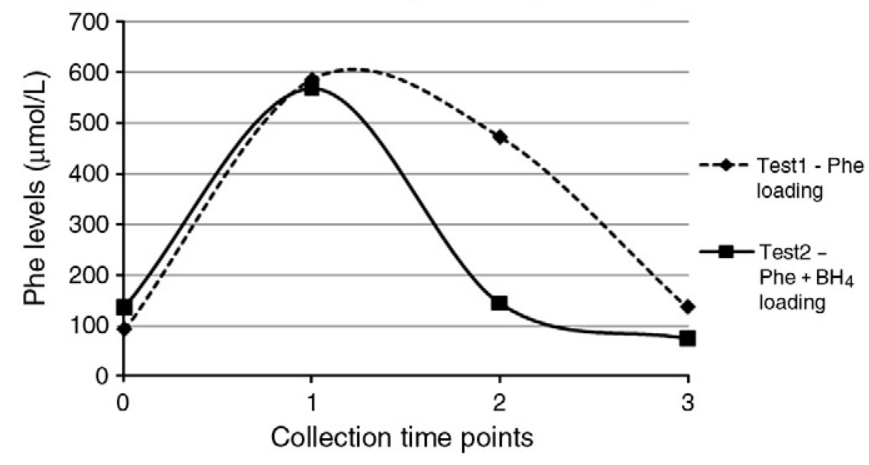

B Patient 14 - Classical PKU (p.R408W/p.R408W)

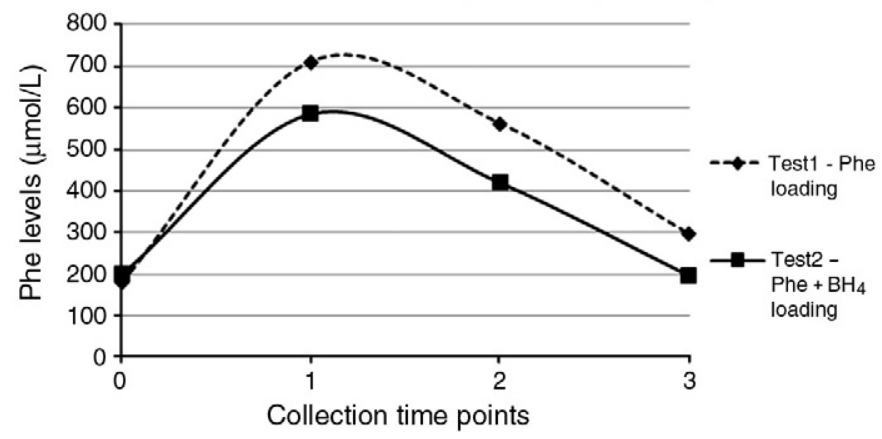

Fig. 1. (A) Phe variation in a patient classified as responsive to $\mathrm{BH}_{4}$ according to collection time points. (B) Phe variation in a patient classified as non-responsive to $\mathrm{BH}_{4}$ according to collection time points.

same patient. The one conducted by Desviat et al. [20] included six patients with Phe level at diagnosis below $360 \mu \mathrm{mol} / \mathrm{L}$, but classified their responsiveness only according to the combined $\mathrm{Phe}+\mathrm{BH}_{4}$ test; and the one conducted by Ponzone et al. [32], which included seven patients with different forms of PKU, but did not establish clear criteria for the classification of responsiveness. The analysis of Phe curves in both studies suggests that Phe plasma levels reach similar values at the end of the simple Phe and combined $\mathrm{Phe}+\mathrm{BH}_{4}$ loading tests; although, Phe levels seem to decrease faster when $\mathrm{BH}_{4}$ is used.

The protocol to evaluate responsiveness in this study is innovative for two reasons: (1) it included the use of a simple Phe and a combined Phe $+\mathrm{BH}_{4}$ loading test for 18 patients with PKU and good metabolic control; (2) it defined $\mathrm{BH}_{4}$ responsiveness parameters based on the comparison of results of these two tests. According to the strategy adopted in this study, $33.3 \%(6 / 18)$ of the patients were classified as responsive, which is in agreement with data in the literature [17$19,23,30,34]$. Of the responsive patients, two had the classical PKU $(n=2 / 8 ; 25.5 \%)$ and four, the mild PKU $(n=4 / 10 ; 40 \%)$, which confirmed that responsiveness is greater among individuals with milder forms of PKU. Moreover, of the 16 patients for whom genotypes were available, six had data about BH4-responsiveness genotypes described in the literature.

There was also an important discordance between the seven criteria used to compare the definition of responsiveness. In the group of 18 individuals, only one was responsive and six were non-responsive according to all criteria. If criteria 4 and 5, which consider the results of combined Phe $+\mathrm{BH}_{4}$ loading only, had not been used, a greater number of patients would have concordant results for non-responsiveness $(n=10)$. The use of criteria 4 and 5 independently seems to lead to a greater number of diagnoses of patients responsive to $\mathrm{BH}_{4}$; this may be explained by the fact that these criteria do not take into consideration that Phe may be excreted spontaneously and not due to $\mathrm{BH}_{4}$ action.
Although the protocol here described has some limitations, e.g. the need for patients to attend the treatment center twice (two consecutive weeks) and to undergo a higher number of blood collections, the superiority of this protocol when compared with others already described in the literature can only be assessed if comparative studies are carried out. This underscores the need for determining the sensitivity, specificity, as well as positive and negative predictive values of these tests, especially if we take into consideration that, as our findings clearly show, patients diagnosed as $\mathrm{BH}_{4}$-responsive according to one given protocol may not be diagnosed as such in another protocol. In this sense, one of the future goals of the authors is to test simple $\mathrm{BH}_{4}$ loading in all patients included in the present study.

\subsection{Comments on dietary ingestion and Phe levels during the Tests}

Dietary Phe ingestion did not change in the two recalls in the same Test, and there was also no variation in the comparison of total Phe amount ingested in Test 1 and in Test 2, which suggests that the fall in Phe levels in responsive individuals was secondary to $\mathrm{BH}_{4}$ administration.

The variation of Phe plasma concentrations along the study revealed an elevation at time point $\mathrm{T} 1$ in comparison with time point T0, that is, $3 \mathrm{~h}$ after Phe loading, which demonstrates, therefore, that L-Phe was absorbed by the patient. The collection point $3 \mathrm{~h}$ after Phe loading was used because it has been described in the literature as the point at which Phe plasma levels peak predominantly [24]. However, in 9 patients in this study, the highest Phe plasma concentration values occurred at least, in one of the Tests, $11 \mathrm{~h}$ after Phe loading, which has also been reported by other studies $[19,20]$.

Phe plasma concentrations at time points 0 and 1 in the two Tests did not differ from each other, which emphasizes their comparability.

\subsection{Conclusions}

$\mathrm{BH}_{4}$ has emerged as a new treatment for patients with mostly milder forms of PKU and may substantially improve their quality of life. Numerous positive findings, including increases in Phe tolerance, have been reported in association with the use of this medication. However, no consensus has been reached about the best method and criteria to define responsiveness to $\mathrm{BH}_{4}$. The validation of methods and criteria for this purpose is fundamental to optimize the treatment with $\mathrm{BH}_{4}$ also in terms of cost and effectiveness. Our data suggest that, in responsive individuals, Phe levels decrease faster after Phe $+\mathrm{BH}_{4}$ loading than after simple Phe loading, and confirm that the comparison between simple Phe and combined Phe $+\mathrm{BH}_{4}$ loading is valid to evaluate responsiveness. Moreover, because of the wide range of variation of responsiveness classification for each patient, more than one criterion should be used to establish a definition, and these criteria should take into consideration the comparison between the values obtained in single Phe and combined Phe $+\mathrm{BH}_{4}$ loading tests.

\section{Acknowledgments}

The authors thank the following: Halfway House, Statistic Unit, FIPE and the staff of the Medical Genetics Service at HCPA. They also thank the Brazilian Coordinating Agency for Advanced Training of Graduate Personnel (CAPES) and Merck Serono for their support and collaboration in this study. This work was supported in part by the Swiss National Science Foundation grant no. 3100A0-1199852/1 (to NB).

\section{References}

[1] C. Scriver, S. Kaufman, Hyperphenylalaninemia: phenylalanine hydroxylase deficiency, in: C. Scriver, A. Beaudet, W. Sly, D. Valle, B. Childs, B. Vogelstein (Eds.), The metabolic and molecular bases of inherited disease, McGraw-Hill, New York, 2001, pp. 1667-1724. 
[2] National Institutes of Health Consensus Development Conference Statement: phenylketonuria: screening and management, October 16-18, 2000 Pediatrics, 108, 2001, pp. 972-982.

[3] C.N. Sarkissian, A. Gamez, C.R. Scriver, What we know that could influence future treatment of phenylketonuria, J. Inherit. Metab. Dis. 32 (2009) 3-9.

[4] N. Blau, F.J. van Spronsen, H.L. Levy, Phenylketonuria, Lancet 376 (2010) 1417-1427.

[5] J.H. Walter, F.J. White, S.K. Hall, A. MacDonald, G. Rylance, A. Boneh, D.E. Francis, G.J. Shortland, M. Schmidt, A. Vail, How practical are recommendations for dietary control in phenylketonuria? Lancet 360 (2002) 55-57.

[6] T. Nalin, I. Perry, L. Refosco, C. Netto, C. Souza, T. Vieira, P. Picon, I. Schwartz, Fenilcetonúria no Sistema Único de Saúde: Avaliação de Adesão ao Tratamento em um Centro de Atendimento do, Rio Grande do Sul Revista HCPA 30 (2010) 222-232.

[7] K.T. Friedrich, K.B. Barbara, L. Nicola, C. Mercedes Martinez-Pardo, J.G. Daniel, D. Alex, D.K. Emil, A.C. Eric, K.G. Dorothy, H. Paul, H.L. Mark, M. Andrzej, R. Linda Marie, V. Jerry, B.W. Chester, A.W. Jon, B. Judith, C.-S. Heidi, B.H. Julia, Efficacy of sapropterin dihydrochloride in increasing phenylalanine tolerance in children with phenylketonuria: a phase III, randomized, double-blind, placebo-controlled study, J. Pediatr. 154 (2009) 700-707.e701.

[8] S. Kure, D.C. Hou, T. Ohura, H. Iwamoto, S. Suzuki, N. Sugiyama, O. Sakamoto, K. Fujii, Y. Matsubara, K. Narisawa, Tetrahydrobiopterin-responsive phenylalanine hydroxylase deficiency, J. Pediatr. 135 (1999) 375-378.

[9] A.C. Muntau, W. Roschinger, M. Habich, H. Demmelmair, B. Hoffmann, C.P. Sommerhoff, A.A. Roscher, Tetrahydrobiopterin as an alternative treatment for mild phenylketonuria, N. Engl. J. Med. 347 (2002) 2122-2132.

[10] L.J. Spaapen, M.E. Rubio-Gozalbo, Tetrahydrobiopterin-responsive phenylalanine hydroxylase deficiency, state of the art, Mol. Genet. Metab. 78 (2003) 93-99.

[11] N. Blau, H. Erlandsen, The metabolic and molecular bases of tetrahydrobiopterinresponsive phenylalanine hydroxylase deficiency, Mol. Genet. Metab. 82 (2004) 101-111.

[12] B. Fiege, L. Bonafe, D. Ballhausen, M. Baumgartner, B. Thony, D. Meili, L. Fiori, M. Giovannini, N. Blau, Extended tetrahydrobiopterin loading test in the diagnosis of cofactor-responsive phenylketonuria: a pilot study, Mol. Genet. Metab. 86 (2005) S91-S95.

[13] G. Gramer, P. Burgard, S.F. Garbade, M. Lindner, Effects and clinical significance of tetrahydrobiopterin supplementation in phenylalanine hydroxylase-deficient hyperphenylalaninaemia, J. Inherit. Metab. Dis. 30 (2007) 556-562.

[14] U. Langenbeck, Classifying tetrahydrobiopterin responsiveness in the hyperphenylalaninaemias, J. Inherit. Metab. Dis. 31 (2008) 67-72.

[15] G. Gramer, S.F. Garbade, N. Blau, M. Lindner, Pharmacokinetics of tetrahydrobiopterin following oral loadings with three single dosages in patients with phenylketonuria, J. Inherit. Metab. Dis. 32 (2009) 52-57.

[16] C.O. Harding, New era in treatment for phenylketonuria: pharmacologic therapy with sapropterin dihydrochloride, Biologics 4 (2010) 231-236.

[17] B.K. Burton, D.K. Grange, A. Milanowski, G. Vockley, F. Feillet, E.A. Crombez, V. Abadie, C.O. Harding, S. Cederbaum, D. Dobbelaere, A. Smith, A. Dorenbaum, The response of patients with phenylketonuria and elevated serum phenylalanine to treatment with oral sapropterin dihydrochloride (6R-tetrahydrobiopterin): a phase II, multicentre, open-label, screening study, J. Inherit. Metab. Dis. 30 (2007) 700-707.

[18] H.L. Levy, A Milanowski, A. Chakrapani, M. Cleary, P. Lee, F.K. Trefz, C.B. Whitley, F. Feillet, A.S. Feigenbaum, J.D. Bebchuk, H. Christ-Schmidt, A. Dorenbaum, Efficacy of sapropterin dihydrochloride (tetrahydrobiopterin, 6R-BH4) for reduction of phenylalanine concentration in patients with phenylketonuria: a phase III randomised placebo-controlled study, Lancet 370 (2007) 504-510.
[19] B. Perez-Duenas, M.A. Vilaseca, A. Mas, N. Lambruschini, R. Artuch, L. Gomez, J. Pineda, A. Gutierrez, M. Mila, J. Campistol, Tetrahydrobiopterin responsiveness in patients with phenylketonuria, Clin. Biochem. 37 (2004) 1083-1090.

[20] L.R. Desviat, B. Perez, A. Belanger-Quintana, M. Castro, C. Aguado, A. Sanchez, M.J. Garcia, M. Martinez-Pardo, M. Ugarte, Tetrahydrobiopterin responsiveness: results of the BH4 loading test in 31 Spanish PKU patients and correlation with their genotype, Mol. Genet. Metab. 83 (2004) 157-162.

[21] N. Blau, A. Belanger-Quintana, M. Demirkol, F. Feillet, M. Giovannini, A. MacDonald, F.K. Trefz, F. van Spronsen, Management of phenylketonuria in Europe: survey results from 19 countries, Mol. Genet. Metab. 99 (2010) 109-115.

[22] F.K. Trefz, B.K. Burton, N. Longo, M.M. Casanova, D.J. Gruskin, A. Dorenbaum, E.D. Kakkis, E.A. Crombez, D.K. Grange, P. Harmatz, M.H. Lipson, A. Milanowski, L.M. Randolph, J. Vockley, C.B. Whitley, J.A. Wolff, J. Bebchuk, H. Christ-Schmidt, J.B. Hennermann, Efficacy of sapropterin dihydrochloride in increasing phenylalanine tolerance in children with phenylketonuria: a phase III, randomized, doubleblind, placebo-controlled study, J. Pediatr. 154 (2009) 700-707.

[23] L. Giugliani, A. Sitta, C.R. Vargas, L.C.S. da Silva, T. Nalin, M.L. Saraiva-Pereira, R. Giugliani, I.V.D. Schwartz, Responsividade à tetrahidrobiopterina em pacientes brasileiros com deficiência de fenilalanina hidroxilase, J. Pediatr. 87 (2011) 245-251.

[24] N. Blau, B. Fiege, F. Trefz, Tetrahydrobiopterin-responsive phenylalanine hydroxylase deficiency: diagnosis, treatment, genetics, and international BIOPKU database, in: N. Blau, B. Thfny (Eds.), Pterins, Folates and Neurotransmitters in Molecular Medicine, Verlagsgesellschaft mbH, Heilbronn,Germany, 2004, pp. 132-142.

[25] M.S. Rashed, P.T. Ozand, M.P. Bucknall, D. Little, Diagnosis of inborn errors of metabolism from blood spots by acylcarnitines and amino acids profiling using automated electrospray tandem mass spectrometry, Pediatr. Res. 38 (1995) 324-331.

[26] T. Opladen, B. Abu Seda, A. Rassi, B. Thony, G.F. Hoffmann, N. Blau, Diagnosis of tetrahydrobiopterin deficiency using filter paper blood spots: further development of the method and 5 years experience, J. Inherit. Metab. Dis. 34 (2011) 819-826.

[27] N. Blau, B.K. Burton, B. Thöny, F.J.v. Sprosen, S. Waisbren, Phenylketonuria and BH4 Deficiencies, UNI-MED, Bremen, 2010

[28] J.B. Nielsen, K.E. Nielsen, F. Guttler, Tetrahydrobiopterin responsiveness after extended loading test of 12 Danish PKU patients with the Y414C mutation, J. Inherit. Metab. Dis. 33 (2010) 9-16.

[29] B.K. Burton, H. Bausell, R. Katz, H. Laduca, C. Sullivan, Sapropterin therapy increases stability of blood phenylalanine levels in patients with BH4-responsive phenylketonuria (PKU), Mol. Genet. Metab. 101 (2010) 110-114.

[30] A. Bélanger-Quintana, M.J. García, M. Castro, L.R. Desviat, B. Pérez, B. Mejía, M. Ugarte, M. Martínez-Pardo, Spanish BH4-responsive phenylalanine hydroxylasedeficient patients: evolution of seven patients on long-term treatment with tetrahydrobiopterin, Mol. Genet. Metab. 86 (2005) 61-66.

[31] A. Baldellou Vázquez, M.I. Salazar García-Blanco, M.P. Ruiz-Echarri Zalaya, C. Campos Calleja, L. Ruiz Desviat, M. Ugarte Pérez, Tratamiento de la hiperfenilalaninemia por déficit de fenilalanina hidroxilasa con tetrahidrobiopterina. ¿Cuándo y cómo? Anales de Pediatría 64 (2006) 146-152.

[32] A. Ponzone, F. Porta, A. Mussa, A. Alluto, S. Ferraris, M. Spada, Unresponsiveness to tetrahydrobiopterin of phenylalanine hydroxylase deficiency, Metabolism 59 (2010) 645-652.

[33] J.J. Mitchell, B. Wilcken, I. Alexander, C. Ellaway, H. O'Grady, V. Wiley, J. Earl, J. Christodoulou, Tetrahydrobiopterin-responsive phenylketonuria: the New South Wales experience, Mol. Genet. Metab. 86 (2005) S81-S85.

[34] B. Fiege, N. Blau, Assessment of tetrahydrobiopterin (BH4) responsiveness in phenylketonuria, J. Pediatr. 150 (2007) 627-630. 